\title{
Breast Adenosis
}

National Cancer Institute

\section{Source}

National Cancer Institute. Breast Adenosis. NCI Thesaurus. Code C3484.

A non-neoplastic disorder characterized by epithelial and/or myoepithelial tissue growth in the breast lobules. It may be associated with apocrine changes or sclerosis. 